\section{Successful Percutaneous Coronary Intervention to Single Coronary Artery From the Right Sinus of Valsalva}

Yumi Ishii, MD; Hidefumi Akioka, MD;

Kunio Yufu, MD, PhD; Kyoko Kawano, MD;

Miho Miyoshi, MD; Takaaki Imamura, MD;

Reika Ayabe, MD; Hidekazu Kondo, MD, PhD;

Shotaro Saito, MD, PhD; Akira Fukui, MD, PhD;

Norihiro Okada, MD, PhD; Tetsuji Shinohara, MD, PhD;

Yasushi Teshima, MD, PhD;

Mikiko Nakagawa, MD, PhD;

Naohiko Takahashi, MD, PhD

A n 89-year-old woman visited hospital with chest pain. Troponin T was rising $(0.032 \mu \mathrm{g} / \mathrm{mL})$. Twelvelead electrocardiogram showed ST elevation in aVR and ST depression in V2-5, and these changes were improved by nitroglycerin. The patient was therefore diagnosed with unstable angina. Computed tomography angiography (CTA) showed a single coronary artery arising from the right coronary ostium (Figure A-C). The left coronary artery with a long transverse trunk crossed in front of the pulmonary artery (Figure B). The long left main coronary trunk had severe stenosis with rich plaque. Coronary angiography showed a lesion compatible with that seen on CTA (Figure D). We chose percutaneous coronary intervention (PCI) but not coronary artery bypass grafting because of the high STS score $(6.385 \%)$ and emergency status. We selected Heartrail ${ }^{\circledR}$ Ikari Left 4.0 (Terumo, Japan) to provide appropriate backup without injury. The drug-eluting stent was deployed (Figure E). After PCI, the symptom disappeared.

The present single coronary artery was type R-IIA according to Lipton classification; type R-II patients comprise $0.015 \%$ of the population. ${ }^{1}$ Only one report has previously described PCI for type R-IIA. ${ }^{2}$ The coronary lesion in that report was at the same position as in the present case. The turbulence might occur morphologically in this anomaly, impairing the vascular endothelium.

\section{Disclosures}

The authors declare no conflicts of interest.

\section{References}

1. Lipton MJ, Barry WH, Obrez I, Silverman JF, Wexler L. Isolated single coronary artery: Diagnosis, angiographic classification, and clinical significance. Radiology 1979; 130: 39-47.

2. Khanal S, Vijayvergiya R, Singhal M. PCI in a single coronary artery from right aortic sinus: A rare case. Indian Heart J 2015; 67: $141-143$.

Received May 11, 2018; revised manuscript received June 8, 2018; accepted June 25, 2018; J-STAGE Advance Publication released online August 29, 2018 Time for primary review: 25 days

Department of Cardiology and Clinical Examination, Faculty of Medicine, Oita University, Yufu, Japan

Mailing address: Yumi Ishii, MD, Department of Cardiology and Clinical Examination, Faculty of Medicine, Oita University, 1-1 Idaigaoka, Hasama, Yufu 879-5593, Japan. E-mail: yumiishii@, oita-u.ac.jp

ISSN-1346-9843 All rights are reserved to the Japanese Circulation Society. For permissions, please e-mail: cj@j-circ.or.jp
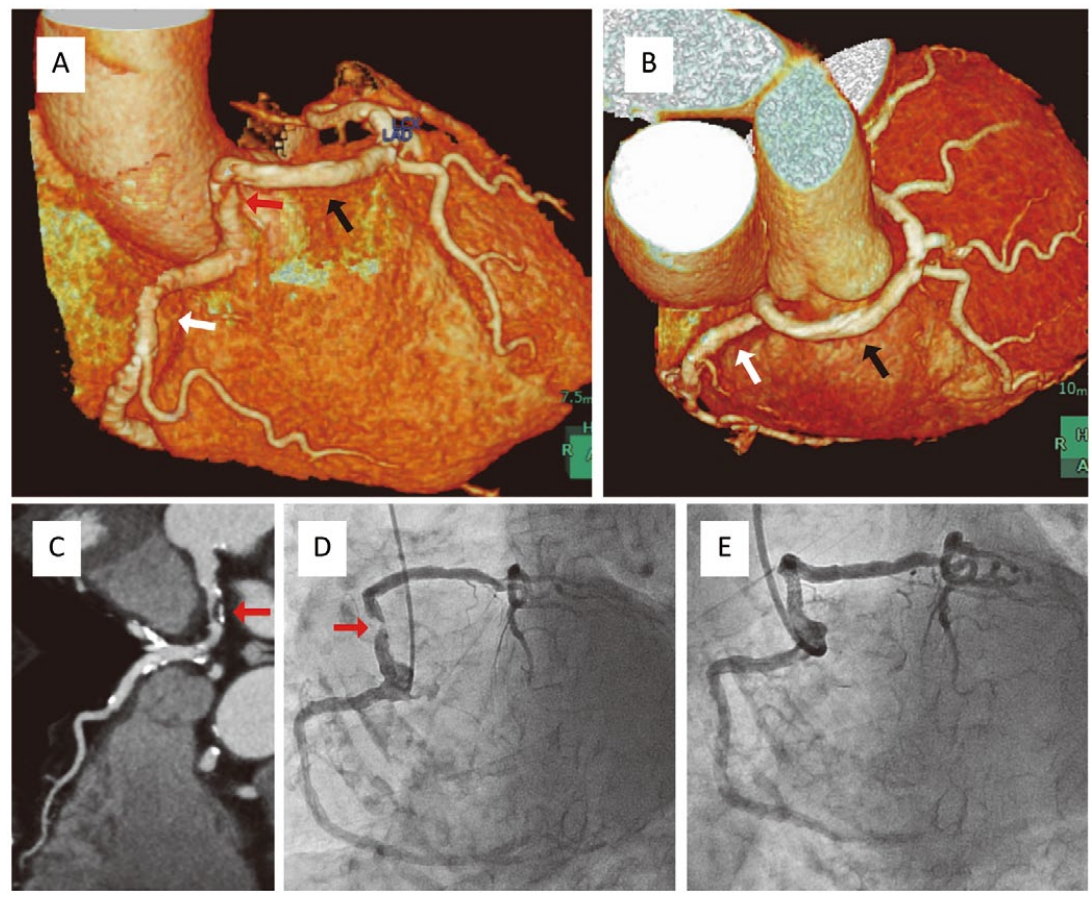

Figure. (A,B) Computed tomography (CT) angiography with volume rendering showing the severely stenotic lesion (red arrow) and the single coronary artery with left main coronary trunk (LMT; black arrow) arising from a normal right coronary artery $(\mathrm{RCA}$; white arrow). (C) CT angiography with curved planar reconstruction showing a $90 \%$ stenotic lesion (red arrow) in the middle of the LMT. (D,E) Coronary angiography (left anterior oblique caudal view) showing (D) the left coronary artery diverging at $90^{\circ}$ from the RCA and the same 90\% stenotic lesion (red arrow) as on CT, and (E) successful percutaneous coronary intervention. $L A D$, left anterior descending coronary artery; LCX, left circumflex coronary artery. 